\title{
Explaining the Human Resource Management Preferences of Employees: A Study of Chinese Workers
}

\begin{abstract}
This study explores the human resource management preferences of Chinese employees, based on a sample of 2852 questionnaires from organizations in China. The research findings show a strong 'group orientation' and a great emphasis on 'soft factors' such as seniority, loyalty and connections in many HRM areas. It is argued that certain areas of Chinese HRM are converging to the western model, but the influence of traditional Chinese personnel practices remains strong. A 'group orientation', a major emphasis on 'soft factors' and a trade union presence will remain as the three main features of Chinese HRM in the long term.
\end{abstract}

Keywords

China; Chinese; Convergence; Divergence; HRM; HRM Preferences

\section{Introduction}

There have been a number of studies on the convergence and divergence trends in HRM between China and western countries (Warner, 1993, 1997, 2002a, b, 2003, 2009b; Saner and Yiu, 1994; Easterby-Smith, Malina and Yuan, 1995; Verburg, Drenth, Koopman, Muijen and Wang, 1999; Aycan et al., 2000; Peppas, Peppas and Jin, 2001; Huo, Huang and Kapier, 2002; Hutchings, 2003; Selmer, 2005; Cunningham and Rowley, 2008). Many studies have examined convergent and divergent trends at the macro level, 
focusing on the forces of globalization, technology and differences in political systems, legal systems and industrial relations systems. The forces of globalization, technology and the differences or similarities in institutional systems place substantial pressure on convergence and divergence in HRM practices. Moreover, local customs and the responses from employees also pose serious constraints on the degree of convergence or divergence (Rowley and Benson, 2002). In other words, there is what might be termed an upward influence coming from the employees. While companies may benchmark HRM 'best practices', the actual adoption and success of these practices depends, to a large extent, on perceptions and acceptance from employees.

Despite this, the opinions of non-managerial employees have been largely neglected in the studies of HRM (Legge, 1995; Guest, 2002; Edgar and Geare, 2005; Qiao, Khilji and Wang, 2009). Cooke (2009), after reviewing studies on HRM in China published between 1998 and 2007 in major business and management journals, reported that twothirds of the studies had collected data from managers and most of them relied on managers as the sole source for information. Since the information has mainly been provided by managers, there is the potential for bias because feedback from the managers probably reflects the ideal or 'best practices' of HRM that those managers want to implement, rather than the actual HR policies or practices being used in the organization. Thus Cooke (2009, p.19) argued that 'unless we can broaden our research catchment to include views from the widest range of stakeholders, particularly the employees, our understanding of HRM in China remains partial, from management's lens'. 
This study will explore the HR preferences of Chinese employees, both non-managerial and managerial ones. A number of questions will be explored. For example, what do they think of a 'promotion-from-within' policy? Do they prefer an individual-based bonus or a group-based bonus? Do they prefer a 'downward performance appraisal method' or a 'multi-source performance appraisal method'? In the following section, research hypotheses of HRM preferences of Chinese employees are developed based on Schuler and Jackson's (1987) HRM menu. When developing research hypotheses, it is assumed that existing HR practices both consider and reflect employees' preferences.

\section{Research Hypotheses}

\section{HRM Preferences - Planning}

In China's centrally-planned economy system before the mid-1980s, human resource planning was conducted by central or local governments to support the central labour allocation system. At the organizational level, job analysis was rarely conducted, person specifications were implicit and the job instructions were only broadly specified. This system was reformed in the 1990s. However, the influence of the traditional Chinese personnel management system has only been eliminated gradually (Warner, 1996, 2009a, b; Hassard, Sheehan and Morris, 1999; Morris, Sheehan and Hassard, 2001; Hassard, Morris and Sheehan, 2004). Most companies had a formal HR system administered by the HR department and there was little evidence of devolvement of HRM to line managers (Zhu and Dowling, 2002; Zhu, Cooper, Cieri, Thomson and Zhao, 2009; Zou and Lansbury, 2009). However, this 'formal' HR system, in both indigenous and foreign 
companies, was non-strategic in nature (Warner, 2009b). Lin (2004), in a state-run large scale survey on HRM in China during the transitional period, reported that only $16.7 \%$ of companies had human resource planning linked with corporate strategy. The survey also showed that only $51.8 \%$ companies conducted job analysis and $43.4 \%$ companies used job instructions. Therefore, it is hypothesized that

Hypothesis 1. Chinese employees would show a preference for 'formal HR planning by HR department' over 'informal HR planning based on interdepartmental cooperation'.

Hypothesis 2. Chinese employees would show a preference for 'long term HR planning' over 'short term HR planning'.

Hypothesis 3. Chinese employees would tend to think "job analysis is not important' rather than 'important'.

Hypothesis 4. Chinese employees would show a preference for 'selection criteria for reference purposes only' over 'selection criteria should be explicit and strictly followed'.

Hypothesis 5. Chinese employees would show a preference for 'broad job instruction' over 'comprehensive and detailed job instruction'.

Hypothesis 6. Chinese employees would tend to think 'HR department should focus on personnel management' over 'HR department should be involved in company's strategic planning'. 
Culturally, China has a 'high power distance' and 'high collectivism' (Hofstede, 2001; Humborstad, Humborstad, Whitfield and Perry, 2008). High power distance indicates a lower preference for empowerment and flat organizational structure while strong collectivism indicates less resistance for cross-departmental job design. Therefore, it is hypothesized that

Hypothesis 7. Chinese employees would prefer to 'keep current organizational structure' over 'a flat organizational structure which minimizes management levels'.

Hypothesis 8. Chinese employees would prefer a 'job design which encourages cross-departmental cooperation' over one 'avoids cross-departmental cooperation'.

\section{HRM Preferences - Staffing}

China is a country with a high level of collectivism. Central to the collectivist view of life is the distinction between 'in-groups' and 'out-groups', the former being trusted and taken care of, the latter being suspicious and excluded. Preferential treatment for 'ingroups' are expected and tolerated. This cultural influence on Chinese HR practices has been observed in many studies. For example, Easterby-Smith et al. (1995) reported that managerial careers mostly evolved within the same function and that cross-functional moves were rare. Moreover, managerial posts were normally filled internally. Zhu and Dowling (2002) reported that traditional Chinese staffing practices such as the 'inheritance of job' (the inheritance of jobs from parents to offspring) which were 
believed to have ended, still existed in both indigenous and foreign companies. Therefore, it is hypothesized that

Hypothesis 9. Chinese employees would show a preference towards 'recruitment from within' over 'recruiting the most suitable candidates regardless of internal or external sources'.

Hypothesis 10. Chinese employees would show a preference towards 'promotion from the same department' over 'promoting the best candidates regardless of internal or external sources'.

Hypothesis 11. Chinese employees would show a preference towards a 'narrow career path which encourages transfer and promotion within same functional department' (preference for 'ingroups') over a 'board career path which encourages transfer and promotion between different functional departments'.

In Chinese traditional staffing practices, recruitment and promotion followed four principles: 'good moral practice' (de), 'adequate competence' (neng), 'hard working' (qin) and 'strong performance record' (ji). Priority was given to subjective criteria such as political loyalty, moral standards and the ability to maintain harmonious relations with colleagues (Child, 1994). Easterby-Smith et al. (1995), Morris and Shen (2002) and Zhu and Dowling (2002) all reported that these 'soft' criteria were significantly important in recruitment and promotion. Since the economic reform, Chinese staffing practices have gradually moved away from the 'political and relationship oriented' system to a 'market oriented' one. This change includes more open and transparent staffing procedures, more 
specific criteria, more emphasis placed on 'hard' and objective criteria such as qualifications, past performance record and competences. This move has led to changes in the use of selection methods. Apart from interviews, many Chinese companies have added different types of tests in their selection process. The results of such tests were more important than an interview in recruitment in Chinese organizations (Huo et al., 2002; Zhu and Dowling, 2002). Therefore, it is hypothesized that

Hypothesis 12. Chinese employees would show a preference towards 'open and explicit recruitment criteria' over 'implicit recruitment criteria'.

Hypothesis 13. Chinese employees would show a preference towards 'selection based on hard criteria such as qualifications and degrees' over 'selection based on soft criteria such as teamwork and interpersonal skills'.

Hypothesis 14. Chinese employees would show a preference towards 'explicit and open promotion criteria' over 'implicit promotion criteria which allows managerial judgement'.

Hypothesis 15. Chinese employees would show a preference towards 'promotion based on achievements and abilities' over 'promotion based on loyalty and seniority'.

Hypothesis 16. Chinese employees would show a preference towards the 'use various selection methods including tests in recruitment' over the 'use single instrument such as interview in recruitment'. 


\section{HRM Preferences - Performance Appraisal}

Before the economic reform, performance appraisal in China was a practice used in large SOEs and they only focused on managers. It normally started with a self report, followed by a review by senior managers and sometimes feedback from subordinates. Performance appraisal criteria were behaviour-based and subjective, including political loyalty, ideological purity and seniority (Child, 1994; Taormina and Gao, 2009), which inevitably led to problems such as subjectivity, vagueness, favouritism and domination of political ideology (Zhu, 2005). The performance appraisal system has moved to a more resultsoriented one since the 1990s (Ding, Akhtar and Ge, 2009). Lin (2004), for example, reported that performance appraisal had become more objective, with $86.9 \%$ of companies using performance record and skill levels as the main criteria, while only $10.7 \%$ of companies using attitudes and behaviours as the main criteria. Many western appraisal methods such as Management by Objectives (MBO), 360-degree performance appraisal and Balanced Score Card (BSC) have been used in Chinese companies. Performance appraisal was linked closely with pay. The results of performance appraisal were mainly used for bonuses allocation, pay rise and promotion. It is expected that Chinese employees would show greater interest in the design and delivery of performance appraisal because of the close link between performance appraisal and pay and promotion. Therefore, it is hypothesized that

Hypothesis 17. Chinese employees would show a preference towards 'appraisal of results' over 'appraisal of behaviours'. 
Hypothesis 18. Chinese employees would show a preference towards 'employee participation in the design of appraisal system' over the 'managers determine appraisal system'.

Hypothesis 19. Chinese employees would show a preference towards 'upward appraisal in which subordinates evaluate managers' over 'downward appraisal in which only the manager evaluates subordinates'.

Hypothesis 20. Chinese employees would show a preference towards 'individually-based appraisal' over 'group-based appraisal'.

Hypothesis 21. Chinese employees would show a preference towards 'disclosing appraisal results to all employees' over 'keeping results confidential, only known by the manager and the individual'.

Hypothesis 22. Chinese employees would agree that 'performance appraisal is for pay-related purpose such as bonus allocation and promotion' rather than 'to identify developmental needs'.

Because of the high level of collectivism and the close link between performance appraisal and pay, there could be a tendency to exclude external appraisers in order to reduce uncertainty. It is therefore hypothesized that

Hypothesis 23. Chinese employees would show a preference towards 'appraisal should be conducted internally within the company' over 'inviting external appraisers such as customers'. 
Lin (2004) showed that an annual performance appraisal was the most common form, followed by quarterly-based ones. It is therefore hypothesized that

Hypothesis 24. Chinese employees would show a preference towards 'infrequent appraisal, yearly based' over 'frequent appraisal, monthly based'.

\section{HRM Preferences - Compensation}

In the last three decades, compensation practices in Chinese companies have changed greatly. Before the 1978 economic reform, an egalitarian wage policy was adopted, together with unified job allocation, lifetime employment and cradle-to-grave welfare (Ding et al., 2009). In the 1980s, a 'structural wage system' which consisted of 'basic pay', 'position pay', 'seniority pay' and 'bonus' and a 'floating wage system', based on a company's profit level and job responsibility, were used to stimulate productivity. In the 1990s, a 'post-plus skill wage system' was introduced. Pay was determined by job responsibility, skill level, labour intensity and working conditions. Thus a more marketbased pay system has become a popular practice in SOEs, private companies, foreign companies and joint ventures (Ding and Warner, 2001). In a more recent survey, Lin (2004) reported that pay package mainly consisted of 'job responsibility pay', 'bonuses', 'benefits', 'position-related pay', 'skill-related pay' and 'seniority-based pay'. In a typical pay packages, $40 \%$ of pay was performance-related pay. The survey showed that pay has become more market and performance-based. Therefore, it is hypothesized that 
Hypothesis 25. Chinese employees would show a preference towards 'pay should be based on performance' over 'pay should be based on position'.

Hypothesis 26. Chinese employees would show a preference towards 'pay reflects market rate' over 'pay based on company tradition'.

Hypothesis 27. Chinese employees would show a preference towards 'pay should consider qualifications and skill levels' over 'no need to consider such factors'.

Chinese companies have reformed their pay practices in the last three decades in order to stimulate productivity (Ding et al., 2009). However, there is also some evidence that many traditional practices, such as lifetime or long term employment, group-based bonuses, comprehensive welfare package and seniority-based pay have been retained (Easterby-Smith et al., 1995; Goodall and Warner, 1997; Hassard et al., 2004; Walsh and Zhu, 2007). There is a tendency to minimize the pay gap between employees of the same grade, especially in SOEs. Therefore, it is hypothesized that

Hypothesis 28. Chinese employees would show a preference towards 'high employment security' over 'low employment security'.

Hypothesis 29. Chinese employees would show a preference towards 'group-based bonuses' over 'individually-based bonuses'.

Hypothesis 30. Chinese employees would show a preference towards a 'lower salary, higher welfare' policy over a 'higher salary, lower welfare' policy.

Hypothesis 31. Chinese employees would show a preference towards a 'standardized pay package' over a 'flexible pay package'. 
Hypothesis 32. Chinese employees would show a preference towards 'pay should consider seniority' over 'pay only reflects performance'.

Hypothesis 33. Chinese employees would show a preference towards 'company should reward long term service' over 'no need to consider long term service'.

Hypothesis 34. Chinese employees would show a preference towards 'pay reflects internal equality which minimizes differential between employees of the same grade' over 'pay reflects external equality, following the market rate'.

A strong materialistic orientation has been recently observed in the Chinese society (Tung and Baumann, 2009). Lin (2004), for example, showed that most incentives offered by Chinese companies were short-term based, with only $7 \%$ of companies using long-term-based motivation ones. Therefore, it is hypothesized that

Hypothesis 35. Chinese employees would show a preference towards 'monetary reward' over 'non-monetary reward'.

Hypothesis 36. Chinese employees would show a preference towards 'short-term incentives such as bonuses' over 'long term incentives such as employee shares'.

Culturally, Chinese society has a high level of collectivism and high 'power distance' (Hofstede, 2001). It is therefore hypothesized that

Hypothesis 37. Chinese employees would show a preference towards 'privileges for managers are acceptable' over 'privileges for managers are unacceptable'. 
Hypothesis 38. Chinese employees would show a preference towards 'disclose individual pay level' over 'keep individual pay level confidential'.

\section{HRM Preferences - Training and Development}

Warner (1993) noted that training in China was narrowly defined, lacking the western notions of training for long term staff development. Lin (2004), meanwhile, showed both indigenous and foreign companies did not have a long term training and development plan. Only $15 \%$ of companies conducted career planning for their employees. Verburg et al. (1996) and Bjorkman and Lu (1999) argued that there was a tendency to prioritize technical training over management training. In a study of international joint ventures in China, Leung and Kwong (2003) reported that the notion of a 'fast track' was alien to Chinese partners. Elite training is considered to be unacceptable, often leading to poor teamwork and destructive competition. To Chinese partners, training should be operated under an equality rule and across the board. Branine (2005) also noted that education and training in China was provided to everyone, rather than only to key employees. It is therefore hypothesized that

Hypothesis 39. Chinese employees would show a preference towards 'training to improve skills for the present job' over 'training to improve various skills for present and future jobs'.

Hypothesis 40. Chinese employees would show a preference towards 'training based on changes in production or services' over 'systematic and continuous training'. 
Hypothesis 41. Chinese employees would show a preference towards 'training to improve technical skills' over 'training to improve managerial skills'.

Hypothesis 42. Chinese employees would show a preference towards 'training based on company's needs' over 'training based on individual needs'.

Hypothesis 43. Chinese employees would show a preference towards 'providing training for all employees' over 'providing training for key employees only'.

Hypothesis 44. Chinese employees would show a preference towards 'allocation of training opportunity based on group needs' over 'allocation of training opportunity based on individual needs'.

Hypothesis 45. Chinese employees would show a preference towards 'employees should be responsible for their own career planning' over the 'company should be responsible for employees' career planning'.

\section{Methodology}

The HRM Preference Questionnaire (HRMPQ) was used in this research, based on the typology of HRM by Schuler and Jackson (1987). In addition, certain items in the questionnaire were based on the questionnaire designed by Sparrow and Wu (1998). In total, there were 45 pairs of HR choices under 5 main HR functions, namely, planning, staffing, appraisal, compensation, and training and development. In each pair, there were two alternative HR practices, measured by a seven point scale. If the respondent had a preference for the left hand choice, they should circle the value of 1,2 or 3 . The lower the value, the stronger the preference they had for the left hand choice. If the respondent had 
a preference for the right hand choice, they should circle the value of 5,6 or 7 . The higher the value, the stronger the preference they had for the right hand choice. If the respondent circled 4, they were considered to be neutral on this HR practice.

The main purpose of this research was to explore the HRM preferences of Chinese employees. This requires that the company they work for has a working HRM system which covers the main HRM functions. Although there was no absolute rule for projecting whether a company had a working HRM system, the general rule was that the bigger the company, the greater the demand for a formal and systematic HRM system. Therefore, only those companies with a minimum size of 200 employees were included in the sample.

Certain industrial development parks, commercial associations and local governments in Fujian, Guangdong, Beijing, Shanghai and Henan were contacted in 2004. Key informants in these organizations were briefed about the purpose of the study. They were asked to recommend some companies that were likely to participate in the research. Following this 'snowball' sampling strategy, copies of questionnaires and instructions were sent to key informants in each company. They were informed that the questionnaire was for research purposes only and should be completed anonymously, as stated in the questionnaire. Through these key informants, questionnaires were then distributed randomly to employees in different functional departments. Depending on the size of the company, 20 to 80 questionnaires were distributed in each company. In total, 2852 valid questionnaires from 102 companies were collected between 2005 and 2006, with a 
response rate of above $80 \%$. Most of the companies were from the manufacturing, retail, banking and insurance sectors. Table 1.1 shows the demographic characteristics of the respondents. Table 1.2 shows the results of hypotheses.

\section{Research Findings}

\section{HRM Preferences - Planning}

Table 1.3 shows the human resource planning preferences of Chinese employees. In terms of how HR planning should be conducted, employees showed a very strong preference for a formal system $(\mathrm{P} 1$, mean=1.19). They generally preferred a formal and tight HR planning system conducted by HR specialists from the HR department. Informal and loose HR planning systems were not appreciated. They also supported the idea that a good HR plan should cover a long term horizon such as 5 years and focus on long term needs $(\mathrm{P} 3$, mean=5.02). This strong preference for formal and long term planning could be attributed to the influence of traditional centrally-planned personnel management practices prior to the economic reform. Moreover, there was a strong cultural influence. Culturally, Chinese people have a moderate uncertainty avoidance index and a high long term orientation index (Hofstede, 2001). Both cultural values would have reinforced employees' preference for a formal planning system. Research hypothesis 1 (prefer formal HR planning) and 2 (long term HR planning) were, therefore, both supported. 
The research findings showed that there was a changing view on the role of the HR department. Employees supported the idea that the HR department should not focus on basic personnel management. Instead, the HR department should be involved in strategic planning ( $\mathrm{P} 2$, mean=2.04). Employees also emphasized 'formality' during human resource planning. For them, explicit job analysis was very important (P4, mean=2.91), that the selection criteria for a particular post should be set explicitly and strictly applied $(\mathrm{P} 5$, mean $=2.90)$ and that job instructions should be comprehensive and strictly followed rather than be broad and allow employees to determine how to complete the job (P6, mean=3.10). On the issue of organizational structure, employees showed a relatively weak preference for a flat organizational structure $(\mathrm{P} 7$, mean=3.32) and supported the viewed that job design should avoid cross-departmental cooperation (P8, mean=3.25). Research hypotheses 2 to 8 were, therefore, not supported.

\section{HRM Preferences - Staffing}

Table 1.4 shows the staffing preferences of employees. All research hypotheses (hypotheses 9 to 16) regarding staffing preferences were supported. On recruitment and selection, they emphasized 'transparency' and 'objectivity'. They supported the idea that

recruitment criteria should be made very clear to all job applicants $(\mathrm{S} 1$, mean=2.40) and the use of combined and sophisticated selection methods such as interviews, psychological tests and exams (S2, mean=2.53). 
Employees preferred the use of 'hard'-based selection criteria which can be objectively measured such as vocational qualifications, degrees or achievements. On promotion criteria, employees also supported the idea that "promotion should be mainly determined by achievements and abilities' ( $\mathrm{S} 8$, men=3.45). However, both preferences were moderate. In other words, there was also an emphasis on using 'soft' criteria such as one's ability to fit into the group and maintain a harmonious relationship with colleagues, loyalty and seniority.

There was a strong group orientation in the staffing preferences. When there was a job vacancy or promotion opportunity, employees showed a strong preference for internal applicants whereas selecting the 'best' candidates for the position was less preferred. In general, employees preferred a job vacancy to be filled internally before considering external applicants ( $\mathrm{S} 3$, mean=2.66), or to fill a management position by promoting from within the same department (S4, mean=2.92). Similarly, when asked whether career paths should be broad (encouraging horizontal transfers between different functional departments, which means slow promotion but broad knowledge) or narrow (encouraging vertical transfers between the same functional department at the different levels, which means a quicker promotion with expertise), employees showed a preference for a narrow career path $(\mathrm{S} 7$, mean=4.09), which also reflects a group orientation. In a study on recruitment in China, Han and Han (2009) similarly reported that 'network-based recruitment' was widely used, in which priority was given to candidates who were related to employees in the company. 
A further interesting finding was the preference for recruitment and promotion criteria. On recruitment criteria, making recruitment criteria clear was considered to be very important $(\mathrm{S} 1$, mean $=2.4)$ whereas much less emphasis was placed on making promotion criteria explicit to all employees ( $\mathrm{S} 6$, mean=3.52). A possible explanation is 'hierarchical collectivism' in Chinese society. One important feature of collectivism is the distinction in the treatment between in-group and out-group members. When making the hiring decision, job applicants are considered to be out-group members. Little trust is shown towards out-group members and, therefore, explicit recruitment criteria are considered to be important. By contrast, when making a promotion decision, the applicants are likely to be in-group members because of the 'promotion-from-within' policy adopted by many Chinese companies. There is thus a relatively high level of trust towards internal candidates for promotion. Reinforced by hierarchical relationships and highly-centralized decision-making power in Chinese organizations, employees tend to tolerate implicit promotion criteria, allowing managers to determine promotion based on circumstances.

\section{HRM Preferences - Performance Appraisal}

Table 1.5 shows the performance appraisal preferences of employees. Employees generally did not support the idea that performance appraisal should be results-based but emphasized the appraisal of behaviours, that is, how things are done (A1, mean=4.35). Unlike recruitment and selection criteria, there was a preference for keeping appraisal results only between the manager and individual, rather than making it known to all employees, though the preference was not strong $(\mathrm{A} 3$, mean $=4.30)$. There was a slight 
preference towards a group-based appraisal (A6, mean=4.81). Hypotheses 17, 20 and 21 were, therefore, not supported.

A group orientation was reflected in the performance appraisal preferences. Employees generally regarded that appraisal was a group's 'internal affair'. They believed that appraisal should be conducted internally within the company (A7, mean=2.78). The direct link between appraisal results and pay rises and promotion has further promoted the interest of Chinese employees in participating in the design and employment of appraisal systems. Employees believed that they should be consulted in designing appraisal systems (A4, mean=3.71) and employees' performance should be reviewed by their subordinates or colleagues (upward appraisal) rather than their supervisor (downward appraisal) (A8, mean=4.91). Empirically, Braun and Warner (2002) reported that Chinese employees were not only assessed on predefined objectives but also on how teamwork-oriented a person is or how communicative a person is on the job. Taormina and Gao (2009) also argued that being hard working, loyal and respectful towards senior staff were included in Chinese performance appraisal. This group orientation is very different from common western appraisal methods which focus on individual performance, which some attribute to the cultural distance between China and the West (Brewster, Sparrow and Vernon, 2007).

In the broad sense, performance appraisal has three purposes: administration, development and communication (Schuler and Jackson, 1987). However, the research results showed that Chinese employees generally believed that the main objective of 
appraisal was to provide criteria for pay rises and promotion rather than to help employees identify their performance deficiencies (A2, mean=4.92) and the developmental aspect of performance appraisal was ignored. This finding is consistent with the studies of Verburg et al. (1999), Lin (2004) and Zou and Lansbury (2009).

On the performance appraisal frequency, they preferred a medium to long-term-based appraisal, such as semi-yearly or yearly, rather than short-term-based one, such as monthly or weekly (A5, mean=5.31). Therefore, research hypotheses 18, 19, 22, 23 and 24 were supported.

\section{HRM Preferences - Compensation}

Table 1.6 shows the compensation appraisal preferences of employees. All research hypotheses regarding compensation were supported. The employees, for example, supported the idea that the company should disclose individual pay levels ( $\mathrm{C} 2$, mean=3.34). On the determinants of compensation, many employees emphasized that salary should reflect one's contribution rather than one's position in the hierarchy and that the greater the contribution, the higher the salary $(\mathrm{C} 1$, mean=5.16). Moreover, vocational qualifications and degrees should be taken into account when setting compensation levels $(\mathrm{C} 5$, mean=3.79). Compensation levels should not be based on company traditions, instead, the company should offer a market rate to attract and keep talented employees $(\mathrm{C} 4$, mean $=4.40)$. This indicates that Chinese employees' preferences on compensation are switching from the traditional 'grade-based' salary system (Warner, 
1996) to a more merit-based one. Thus popular western compensation concepts such as performance-related pay and competency-based pay are gaining in acceptance.

However, many compensation preferences reflected the strong influence of traditional Chinese personnel practices, with a group orientation.. First, although employees agreed that compensation should be mainly determined by performance, they also emphasized that soft criteria such as seniority and age should be taken into account $(\mathrm{C} 3$, mean=5.15). Similarly, many employees strongly supported the idea that the company should reward loyalty, for example, rewarding those who have worked for the organization for a long period of time $(\mathrm{C} 6$, mean $=2.26)$. The preference for 'soft' criteria and rewarding loyalty was also observed by Jackson and Bak (1998). In practice, many Chinese companies adopt a 'post-plus-skills' system in which age, position and skills determine $50 \%$ to $80 \%$ of the total payment (Goodall and Warner, 1997; Morris and Shen, 2002; Morris and Yang, 2002; Hassard et al., 2004).

Second, although employees supported a market-related pay, they believed that internal equality was important and pay differentiation between employees of the same grade should be capped $(\mathrm{C} 11$, mean=3.23). In practice, not only is the pay gap between employees of the same grade restricted, but the pay gap between top management and workers is also capped (Bi, 2009; Ding et al., 2009). Easterby-Smith et al. (1995) reported a typical ratio of management/average salary of 4:1 while Ding, Fields and Akhtar (1997) reported that in foreign-owned companies in China, the pay differential was limited. Zhao (2004) reported that the ceiling for the compensation level of top 
managers was capped at no higher than 5 times the average pay of workers. Many local governments in China have also placed a cap at the pay level of top managers in SOEs, with a ratio of management/average salary between 3 to 12 times. $^{1}$

Third, there was a preference for a group-based bonus $(\mathrm{C} 14$, mean=5.22), a common practice in China which constitutes a large proportion of the total compensation package. For example, Lewis (2002) reported while a typical Chinese employee's salary had four elements (monthly pay, a monthly production bonus, an annual profit-related bonus and an annual bonus), with the production and profit-related bonuses equal to between $100 \%$ to $150 \%$ of basic pay. Moreover, all bonuses were group-based, either at a workshop level or at the corporate level. Zou and Lansbury (2009) also showed that bonuses were generally distributed equally among workers at the same grade in a large MNC in China.

Fourth, there was a very strong belief that a company should provide long term employment $(\mathrm{C} 10$, mean $=1.4)$, which also indicates a group orientation. This strong preference for long term employment is supported by Chinese employees and the Chinese government. Although the introduction of the labour contract system in 1986 has undermined traditional lifetime employment practices (Ding, Goodall and Warner, 2000), lifetime employment is retained for certain groups in Chinese organizations. First, older workers and those in SOEs enjoy lifetime employment. In most SOEs, the employees are generally categorized into 'permanent employees', 'contractual employees' and 'temporary employees'. Permanent employees consist of nearly $40 \%$ of the workforce.

\footnotetext{
${ }^{1}$ In Shandong province, it was 3 to 6 times (http://www.sdjw.gov.cn/zcfgshow.asp?id=307 last accessed $6^{\text {th }}$ December, 2009); in Beijing, it was up to 12 times (http://www.hrbgzw.gov.cn/news text.asp?id=3053 last accessed $6^{\text {th }}$ December 2009).
} 
Moreover, while 'contractual employees' and 'temporary employees' are contract-based, most of them have their contract automatically renewed (Hassard et al., 2004). Second, influenced by Chinese competitors, some foreign companies and joint ventures also unofficially offer lifetime employment. For example, Walsh and Zhu (2007) reported that $40 \%$ of the workforce in one joint venture had permanent employment contracts. Third, the Chinese government tends to encourage lifetime employment as it is considered to be one of the main benefits of socialism (Ding and Warner, 2001). According to the new Chinese Labour Law (2008), an employee is entitled to an open-ended employment contract if the employee has been employed by the same employer for 10 consecutive years, the employee is less than 10 years away from statutory retirement age or the employee has completed two consecutive fixed-term labour contracts with the same employer. The trade unions also have more power to negotiate collective contracts. Therefore, the belief in the existence of high employment security among Chinese employees is expected to be further reinforced.

The influence of traditional Chinese personnel practices can also be observed in other compensation preferences. On the components of reward, Chinese employees favoured monetary rewards over non-monetary ones $(\mathrm{C} 7$, mean $=2.49)$ and immediate cash rewards over long-term rewards such as employee shares $(\mathrm{C} 8$, mean=4.92), and had high expectations regarding their welfare package. When facing a 'higher salary/lower welfare' or 'lower salary/higher welfare' situation, there was a preference for lower salaries but a higher welfare policy $(\mathrm{C} 13$, mean $=4.87)$, which indicates the influence of traditional Chinese compensation practices, especially the 'cradle to grave' welfare 
policy. Unlike salaries, which, to a certain extent, have been reformed and become more performance-related, welfare packages remain comprehensive and generous, especially in SOEs. In some large SOEs, such as China Mobile, there are around 30 types of welfare, ranging from an 'ice fee' in the summer to housing funds. The housing funds alone can increase the salary by $20 \%$. In private companies, welfare provision is not so generous but still comprehensive. For example, in Huawei, there are subsidies such as free transportation, free meals, and a monthly 'company credit' worth around RMB 1000 (equivalent to $20 \%$ of a graduate's monthly salary in 2006) which can be used in company-run refectories and supermarkets. Zheng (2007) reported that many foreign companies, such as IBM, Microsoft and Bell, have redesigned their welfare policies, providing similar welfare as SOEs offer, such as interest-free housing loans and other subsidies, in order to remain competitive in the job market. Gamble (2003) also reported that, influenced by Chinese practices, UK retail firms in China have started to provide reimbursement for medical-care costs and meals.

There was also a neutral attitude towards management privileges $(\mathrm{C} 12$, mean=4.00). However, it is worth mentioning that in the present study, most respondents were young and with a higher educational level and many were white-collar workers with some management responsibilities. They were thus likely to enjoy some management privileges, explaining the neutral attitude towards managers' privileges.

\section{HRM Preferences - Training}


Table 1.7 shows the training preferences of Chinese employees. On the frequency of training activities, employees preferred a systematic and continuous training plan (T4, mean=2.96). There was a belief that the organization, rather than individual, should be responsible for employees' career planning $(\mathrm{T} 5$, mean=4.89). Therefore, hypotheses 40 and 45 were not supported.

Many employees believed that the main purpose of training is to improve the skills for their present job $(\mathrm{T} 1$, mean=3.24), rather than to develop skills for the future, with developmental aspects of training to some extent ignored. This was also reported by Warner (1993). There was also a belief that the purpose of training is to improve technical rather than management skills $(\mathrm{T} 2$, mean=2.70). This preference for prioritizing technical over management training was also reported by Bjorkman and Lu (1999) and Verburg et al. (1999).

On the identification of training needs and allocation of training opportunities, employees showed a strong group orientation. It was generally accepted that training should be based on the company's need $(\mathrm{T} 3$, mean=4.81) and the allocation of training opportunities should be based on group needs $(\mathrm{T} 6$, mean=5.54). The group orientation was also reflected in the provision of training opportunities. There was a strong belief that the company should provide training for all employees (T7), which is very different from the common western practice of focusing on elite employees only. Research hypotheses 39, 41, 42, 43 and 44 were, therefore, supported. 


\section{Discussion}

In the last three decades, there have been progressive changes in the management of human resources in China, with more Chinese companies adopting contemporary western HRM policies and practices (Brown and Branine, 1995; Bjorkman, 2002; Bjorkman and Fan, 2002; Hassard et al., 2004; Wang, Bruning and Peng, 2007; Akhtar, Ding and Ge, 2008; Cunningham and Rowley, 2008;). A variety of market-oriented and western-based practices have been used in Chinese companies, covering recruitment and selection (Morris and Zhang, 2001; Ke and Morris, 2002; Morris and Shen, 2002; Zhu and Dowling, 2002; Hassard et al., 2004), performance appraisal (Child, 1994; Zhu, 2005; Taormina and Gao, 2009), compensation (Ding et al., 1997; Verburg et al., 1999; Gamble, 2000, 2006; Morris and Yang, 2002; Zhao, 2004; Ding, Akhtar and Ge, 2006; Bozionelos and Wang, 2007) and training and development (Child, 1994; Morris and Shen, 2002; Ng and Siu, 2004; Gamble, 2006).

One might expect that there could be further convergence towards western HRM policies and practices in the short term but, in the foreseeable future, it is unlikely that there will be a large scale convergence towards the western HRM model for a number of reasons. First, as the institutional perspective argues, differences in the 'national business system' would lead to great differences in the human resources policies and practices at company level (Whitley, 1992; Doremus, Keller, Pauly and Reich, 1998; Warner, 2003). In the last three decades, China has moved from a centrally-planned economic system to a 'socialist market' system. China may look like a capitalist country in many ways but, it is 
fundamentally a 'socialist country' led by a communist party and the official slogan is to 'build a socialism with Chinese characteristics'. Communist ideology has affected the Chinese national business system, including the political, financial, legal and social systems. As the institutional perspective predicts, these 'Chinese characteristics' in the business system will further lead to marked differences between the HRM systems in China and other countries. A typical example of the 'Chinese characteristics' of HRM is the new Chinese Labour Law (2008), which encourages a permanent employment policy. The other example is the Chinese Trade Union Law (1992) which only recognizes the All China Federation of Trade Unions (ACFTU) and the ultimate goal of the ACFTU is to have trade unions in all Chinese companies by 2010 (Economist, 2008).

Second, there are significant differences in cultural values between China and western countries (Hofstede, 2001; Lin and Ho, 2009; Warner, 2009a). The cultural perspective argues that cultural values affect HRM at both 'macro' and 'micro' levels. At the macro level, cultural values influence the development of HRM theories and practices through the force of institutional factors. At the micro level, cultural values shape employees' HRM preferences and further determine the extent to which these policies will actually function effectively (Budhwar and Sparrow, 2002). In the context of China, there is much evidence that traditional Chinese cultural values have a significant influence on HRM policies and practices (Warner, 2000, 2003; Cooke, 2005; Cunningham and Rowley, 2008; Zimmerman, Liu and Buck, 2009). Moreover, as the findings indicate, many of the HRM preferences of Chinese employees are significantly different from their western counterparts. For example, there was a strong emphasis on recruitment-from-within, 
promotion-from-within, group-based bonuses and a salary which takes into account seniority and loyalty.

Thus, a realistic view is that many Chinese HR policies and practices will retain their Chinese features (Rowley, Benson and Warner, 2004; Walsh and Zhu, 2007; Cunningham and Rowley, 2008; Warner, 2009b). It is difficult to predict where Chinese HRM will advance in the long term but in the light of the research findings, the following features are likely to remain in Chinese HRM.

First, Chinese HRM will maintain a high level of group orientation, reflected in nearly all the main HR functional areas. For example, there was a great emphasis on recruitmentfrom-within, promotion-from-within, group-based performance appraisal, peer performance appraisal, compensation reflecting internal equality, group-based bonus and allocating training opportunities on group needs. Empirically, many studies have showed a strong group orientation in staffing (Easterby-Smith et al., 1995; Ding et al., 1997; Whiteley, Cheung and Quan, 2000; Zhu and Dowling, 2002; Han and Han, 2009), performance appraisal (Child, 1994; Easterby-Smith et al., 1995; Braun and Warner, 2002), compensation (Ding et al., 1997; Goodall and Warner, 1997; Verburg et al., 1999; Lewis, 2002; Morris and Shen, 2002; Zhao, 2004; Ding et al., 2006; Zou and Lansbury, 2009) and training and development (Braun and Warner, 2002; Lin, 2004). This group orientation has its roots in communist education and the dominant collectivism, which are unlikely to be weakened in the short term. Therefore, this group orientation is likely to remain as a key feature of Chinese HRM. 
Second, Chinese HRM will probably retain a great emphasis on 'soft' factors such as seniority, connections and loyalty, which are significantly different from policies and practices in most western countries where there is a great emphasis on 'hard' factors. As shown in the research results, many Chinese employees believed that the selection process should consider one's ability to maintain a harmonious relationship with others, that promotion should consider loyalty and seniority and that compensation should consider seniority. This emphasis on 'soft' factors has been reflected in other studies, covering both indigenous and foreign companies in China. For example, loyalty and a harmonious relationship with others are commonly used criteria for staffing (EasterbySmith et al., 1995; Lewis, 2002; Morris and Shen, 2002; Zhu and Dowling, 2002; Han and Han, 2009), performance appraisal (Child, 1994; Easterby-Smith et al., 1995; Braun and Warner, 2002; Hempel, 2008; Taormina and Gao, 2009) and compensation (Goodall and Warner, 1997; Jackson and Bak, 1998; Ding and Warner, 2001; Morris and Shen, 2002; Morris and Yang, 2002; Hassard et al., 2004; Zhu, 2005; Zou and Lansbury, 2009). This preference for 'soft' factors is partly influenced by the high level of collectivism and partly influenced by traditional Chinese personnel practices. While in the last three decades, there have been great changes in Chinese HR policies and practices, this emphasis on 'soft' factors remains as a main feature of managing human resources. It is very likely that this preference will be retained in the future.

Third, if the current strategy and policies on protecting workers' rights are taken seriously, the All China Federation of Trade Union (ACFTU) will gain much greater influence and 
become influential in developing Chinese HRM. In the past, although the ACFTU was the only recognized Chinese union, it did not play an important role in the workplace (Brown and Branine, 1995; Wang, Appelbaum, Degiuli and Lichtenstein, 2009), especially in protecting and advancing worker's interests (Cooke, 2005). More recently, the ACFTU, supported by the Chinese government, has put great effort into promoting workplace influence. The new Chinese Trade Union Law (2001) had provisions for the protection of the rights of union representatives. Both the Chinese government and the ACFTU emphasized that it is unlawful to threaten or dismiss a workers' representative because of the union activities. In 2003, the ACFTU started, for the first time, to recruit rural migrant workers and represent them. Now it has more than 60 million rural migrant workers and the number is still increasing dramatically. By 2008, the ACFTU had more than 1.5 million branches with a total of nearly 200 million members. $73.6 \%$ of foreign companies and $69.56 \%$ of private companies in China have had ACFTU branches ${ }^{2}$. Moreover, the new Chinese Labour Law (2008) further strengthened the power of the union. As a result, its influence has been greatly enhanced and the ambitious goal of the ACFTU is to have branches in all Chinese enterprises by 2010 (Economist, 2008). The development trend of the trade unions in China is very different from most western countries where both the numbers and influence of the trade unions have been declining fast in the last three decades (Verma and Kochan, 2004). If the Chinese government, as it has suggested, enforces these policies on promoting workers' rights seriously, it is very likely that the ACFTU will play a much more important role in the management of human resources (Wang et al., 2009) and this could become one of the main features of

\footnotetext{
${ }^{2}$ Statistics from the ACFTU website http://www.acftu.net/template/10004/file.jsp?cid=201\&aid=72843 last accessed $6^{\text {th }}$ December 2009.
} 
Chinese HRM. However, the ability of the ACFTU to independently challenge the Chinese government must remain in some doubts (Taylor and Li, 2009).

This study has some implications for both HR practitioners and scholars. Many HR practices used in China were imported from the West and then diffused to local firms (Yeung, Warner and Rowley, 2008). When transferring western HR practices, companies should consider their employees' HR preferences and adjust HR policies and practices accordingly. Some of the adjustments may be larger than they expect, especially to western companies. For example, they may need to include seniority as a determinant of compensation in China, whereas such a practice is very likely to run counter to the equal opportunity legislation in western countries. They may need to adopt a 'promotion from within' policy for managerial positions or a 'group-based' bonus system in China, whereas these practices may not be common practices in their home country. The success of these adjustments, or 'localization', depends on a good understanding of the HRM preferences of Chinese employees, as well as local cultural values, legal requirements, traditions and customs. Moreover, Chinese companies should realize that being a Chinese organization does not necessarily mean that they have a good understanding of Chinese employees' HR preferences. As shown in the current study, there were mismatch between companies' policies and employees' expectations, especially in HR planning. There is a need to adjust certain HR practices to reflect the preferences of employees because the success of HR policies, to a large extent, depends on the perception and acceptance of employees. 


\section{Conclusion}

The debate on whether Chinese HRM will converge or diverge towards the western models is still ongoing. Many argue that there could be further convergence towards the western practices because globalization may place substantial pressure on firms to standardize practices and policies (see Chen, Lawler and Bae, 2005). Others argue that HRM is highly context specific in which institutional and cultural forces have enduring influences (see Rowley and Cooke, 2010), which indicates a divergent perspective. The third group supports a 'cross-vergence' view which argues that there will be signs of convergence in certain areas but Chinese HRM will keep its 'Chinese characteristics' (Cooke, 2005, 2010; Yeung et al., 2008; Warner, 2009b). This study supports the 'crossvergence' perspective. It is too early to argue that there will be a distinctive Chinese HRM model as HRM is still in its early development stage in China. But Chinese HRM is likely to evolve towards a 'hybrid' system which incorporates contemporary western HRM practices and certain Chinese practices (Cooke, 2005; Warner, 2009a, b). As the research findings showed, a group orientation, a great emphasis on soft factors such as loyalty and seniority and a strong trade union are likely to be the three main features of Chinese HRM. ${ }^{3}$.

\footnotetext{
${ }^{3}$ Most respondents were from companies in more economically-advanced cities in China, which may be unrepresentative. Moreover, the respondents were mainly young Chinese, under 40 years old (85.5\%), with a higher education (71.4\%) and some management responsibilities $(75.9 \%)$.
} 
This study was one of the first to explore the HR preferences from employee side in China. Future studies may explore the factors that shape Chinese employees' HR preferences or adopt a longitudinal method to explore how Chinese employees' HR preferences change over time. 


\section{References}

Akhtar, S., Ding, D. Z., and Ge, G. L. (2008), "Strategic HRM Practices and Their Impact on Company Performance in Chinese Enterprises," Human Resource Management, 47, 15-32.

Aycan, Z., et al. (2000), "Impact of Culture on Human Resource Management Practices: A 10-Country Comparison," Applied Psychology: An International Review, 49, 192-221.

Bi, X. (2009), "Legislation Drafted to Put Ceiling on Executive Salaries," China Daily (US Edition).

Bjorkman, I. (2002), "The Diffusion of Human Resource Management Practices among Chinese Firms: The Role of Western Multinational Corporations," Asia Pacific Business Review, 9, 43-60.

Bjorkman, I., and Fan, X. (2002), "Human Resource Management and the Performance of Western Firms in China," International Journal of Human Resource Management, 13, 853-864.

Bjorkman, I., and Lu, Y. (1999), "A Corporate Perspective on the Management of Human Resources in China," Journal of World Business, 34, 16-25.

Bozionelos, N., and Wang, L. (2007), "An Investigation on the Attitudes of Chinese Workers Towards Individually Based Performance Related Reward Systems," International Journal of Human Resource Management, 18.

Branine, M. (2005), "Cross-Cultural Training of Managers: An Evaluation of a Management Development Programme for Chinese Managers'," Journal of Management Development, 24, 459-472.

Braun, W. H., and Warner, M. (2002), "Strategic Human Resource Management in Western Multinationals in China: The Differentiation of Practices across Different Ownership Forms," Personnel Review, 31, 553-582.

Brewster, C., Sparrow, P., and Vernon, G. (2007), International Human Resource Management, London: CIPD.

Brown, D. H., and Braine, M. (1995), "Managing People in China's Foreign Trade Corporations: Some Evidence of Change," International Journal of Human Resource Management, 6. 
Budhwar, P. S., and Sparrow, P. (2002), "An Integrative Framework for Understanding Cross-National Human Resource Management Practices," Human Resource Management Review, 12, 377-403.

Chen, S. J., Lawler, J. J., and Bae, J. (2005), "Convergence in Human Resource Systems: A Comparison of Locally Owned and MNC Subsidiaries in Taiwan," Human Resource Management, 44, 237-256.

Child, J. (1994), Management in China during the Age of Reform, Cambridge:

Cambridge University Press.

Cooke, F. L. (2005), HRM, Work and Employment in China, UK: Routledge.

Cooke, F. L. (2009), "A Decade of Transformation of HRM in China: A Review of Literature and Suggestions for Future Studies," Asia Pacific Business Review, 47, 6-42.

Cooke, F. L. (2010), "The Changing Face of Human Resource Management in China," in The Changing Face of Management in China, eds. C. Rowley and F. L. Cooke, Oxon: Routledge.

Cunningham, L. X., and Rowley, C. (2008), "The Development of Chinese Small and Medium Enterprises and Human Resource Management: A Review," Asia Pacific Journal of Human Resources, 46, 353-381.

Ding, D., Fields, D., and Akhtar, S. (1997), "An Empirical Study of Human Resource Management Policies and Practices in Foreign-Invested Enterprises in China: The Case of Shenzhen Special Economic Zone," The International Journal of Human Resource Management, 8, 595-614.

Ding, D. Z., Akhtar, S., and Ge, G. L. (2006), "Organizational Differences in Managerial Compensation and Benefits in Chinese Firms," International Journal of Human Resource Management, 17, 693-715.

Ding, D. Z., Akhtar, S., and Ge, G. L. (2009), "Effects of Inter- and Intra-Hierarchy Wage Dispersions on Firm Performance in Chinese Enterprises," International Journal of Human Resource Management, 20, 2370-2381.

Ding, D. Z., Goodall, K., and Warner, M. (2000), "The End of the 'Iron Rice-Bowl': Whither Chinese Human Resource Management?," International Journal of Human Resource Management, 11, 217-236.

Ding, D. Z., and Warner, M. (2001), "China's Labour-Management System Reforms: Breaking the 'Three Old Irons' (1978-1999)," Asia Pacific Journal of Management, 18, 315-334. 
Doremus, P., Keller, W., Pauly, L., and Reich, S. (1998), The Myth of the Global Corporation, Princeton: Princeton University Press.

Easterby-Smith, M., Malina, D., and Yuan, L. (1995), "How Culture-Sensitive Is HRM? A Comparative Analysis of Practice in Chinese and UK Companies," The International Journal of Human Resource Management, 6, 31-60.

Economist. (2008), "Trade Union in China: Membership Required," The Economist, 31 July 2008.

Edgar, F., and Geare, A. (2005), "HRM Practices and Employee Attitudes: Different Measures - Different Results," Personnel Review, 34, 534-549.

Gamble, J. (2000), "Localizing Management in Foreign-Invested Enterprises in China: Practical, Cultural, and Strategic Perspectives," International Journal of Human Resource Management, 11, 883-903.

Gamble, J. (2003), "Transferring Human Resource Practices from the United Kingdom to China: The Limits and Potential for Convergence," International Journal of Human Resource Management, 14, 369-387.

Gamble, J. (2006), "Introducing Western-Style HRM Practices to China: Shopfloor Perceptions a British Organization in East Asia," International Journal of Human Resource Management, 14.

Goodall, K., and Warner, M. (1997), "Human Resources in Sino-Foreign Joint Ventures: Selected Case Studies in Shanghai, Compared with Beijing," The International Journal of Human Resource Management, 8, 569-595.

Guest, D. (2002), "Human Resource Management, Corporate Performance and Employee Wellbeing: Building the Worker into HRM," Journal of Industrial Relations, 44, 335-358.

Han, J., and Han, J. (2009), "Network-Based Recruiting an Applicant Attraction in China: Insights from Both Organizational and Individual Perspectives," International Journal of Human Resource Management, 20, 2228-2249.

Hassard, J., Morris, J., and Sheehan, J. (2004), "The 'Third Way': The Future of Work and Organization in a 'Corporatized' Chinese Economy," International Journal of Human Resource Management, 15, 314-330.

Hassard, J., Sheehan, J., and Morris, J. (1999), "Enterprise Reform in Post-Deng China," International Studies of Management \& Organization, 29, 54-83.

Hempel, P. S. (2008), "Chinese Reactions to Performance Feedback: Non-Task Attributions of Feedback Intentions," Asia Pacific Journal of Human Resources, 46, 196211. 
Hofstede, G. (2001), Culture's Consequences: Comparing Values, Behaviors, Institutions, and Organizations across Nations, London: Sage.

Humborstad, S. I. W., Humborstad, B., Whitfield, R., and Perry, C. (2008), "Implementation of Empowerment in Chinese High Power-Distance Organizations," International Journal of Human Resource Management, 19, 1349-1364.

Huo, Y., Huang, H., and Kapier, N. (2002), "Divergence or Convergence: A Cross National Comparison of Personnel Selection Practices," Human Resource Management, $41,31-44$.

Hutchings, K. (2003), "Cross-Cultural Preparation of Australian Expatriates in Organisations in China: The Need for Greater Attention to Training," Asia Pacific Journal of Management, 20, 375-396.

Jackson, T., and Bak, M. (1998), "Foreign Companies and Chinese Workers: Employee Motivation in the People's Republic of China," Journal of Organizational Change, 11, 282-301.

Ke, L., and Morris, J. (2002), "A Comparative Study of Career Development in State Owned and Foreign Owned Financial Service Companies in China," Chinese management, organization and HRM working paper 3.

Legge, K. (1995), HRM: Rhetorics and Realities, Basingstoke: McMillan.

Leung, K., and Kwong, J. Y. Y. (2003), "Human Resource Management Practices in International Joint Ventures in Mainland China: A Justice Analysis," Human Resource Management Review, 13, 85-105.

Lewis, P. (2002), "New China - Old Ways? A Case Study of the Prospects for Implementing Human Resource Management Practices in a Chinese State-Owned Enterprise," Employee Relations, 25, 42-61.

Lin, L.-H., and Ho, Y.-L. (2009), "Confucian Dynamism, Culture and Ethical Changes in Chinese Societies - a Comparative Study of China, Taiwan and Hong Kong," International Journal of Human Resource Management, 20, 2402-2417.

Lin, Z. (ed.) (2004), The Chinese HRM Development Survey: Human Resource Management for Chinese Enterprises During Transitional Period (in Chinese), Beijing: The Labour and Social Security Publisher of China.

Morris, J., Sheehan, J., and Hassard, J. (2001), "From Dependency to Definance? WorkUnit Relationships in China's State Enterprise Reforms," Journal of Management Studies, 38, 697-719. 
Morris, J., and Shen, Y. (2002), "An Employment Model with 'Chinese Characteristics': A Case Study of a Chinese SOE," Chinese Management, organization and HRM working paper 4.

Morris, J., and Yang, Q. (2002), "Reward Management in China: Comparative Case Studies of an SOE and an Fie," Chinese Management, organization and HRM working paper 6.

Morris, J., and Zhang, J. (2001), "Effective and Rational Human Resource Allocation: A Study of Differing Ownership Forms in China," Chinese Management, organization and HRM working paper 1 .

Ng, Y. C., and Siu, N. Y. M. (2004), "Training and Enterprise Performance in Transition: Evidence from China," International Journal of Human Resource Management, 15, 878894.

Peppas, S. C., Peppas, S. R., and Jin, K. (2001), "Choosing the Right Employee: Chinese Vs. Us Preferences," Career Development, 6, 100-106.

Qiao, K., Khilji, S., and Wang, X. (2009), "High-Performance Work Systems, Organizational Commitment, and the Role of Demographic Features in the People's Republic of China," International Journal of Human Resource Management, 20, 23112330 .

Rowley, C., and Benson, J. (2002), "Convergence and Divergence in Asian HRM" California Management Review, 44, 90-109.

Rowley, C., Benson, J., and Warner, M. (2004), "Towards an Asian Model of Human Resource Management? A Comparative Analysis of China, Japan and South Korea," International Journal of Human Resource Management, 15, 917-933.

Rowley, C., and Cooke, F. L. (eds.) (2010), The Changing Face of Management in China, Oxon: Routledge.

Saner, R., and Yiu, L. (1994), "European and Asian Resistance to the Use of the American Case Method in Management Training: Possible Cultural and Systemic Incongruencies," The International Journal of Human Resource Management, 5, 953-978.

Schuler, R., and Jackson, S. (1987), "Linking Competitive Strategies with Human Resource Management Practices," Academy of Management Executive, 9, 207-219.

Selmer, J. (2005), "Cross-Cultural Training and Expatriate Adjustment in China: Western Joint Venture Managers," Personnel Review, 34, 68-85.

Sparrow, P., and Wu, P. C. (1998), "Does National Culture Really Matter? Predicting HRM Preferences of Taiwanese Employees," Employee Relations, 20, 26-57. 
Taormina, R. J., and Gao, J. H. (2009), "Identifying Acceptable Performance Appraisal Criteria: An International Perspective," Asia Pacific Journal of Human Resources, 47, 102-125.

Taylor, B., and Li, Q. (2009), "Is the ACFTU a Union and Does it Matter?," Journal of Industrial Relations, 49, 701-715.

Tung, R. L., and Baumann, C. (2009), "Comparing the Attitudes toward Money, Material Possessions and Savings of Overseas Chinese Vis-a-Vis Chinese in China: Convergence, Divergence or Cross-Vergence, Vis-a-Vis 'One Size Fits All' Human Resource Management Policies and Practices," International Journal of Human Resource Management, 20, 2382-2401.

Verburg, R. M., Drenth, P. J. D., Koopman, P. L., Muijen, J. J. V., and Wang, Z.-M. (1999), "Managing Human Resources across Culture: A Comparative Analysis of Practices in Industrial Enterprises in China and the Netherlands," The International Journal of Human Resource Management, 10, 391-410.

Verma, A., and Kochan, T. (2004), "Unions in the 21st Century: Prospect for Renewal," in Unions in the 21 Century: An International Perspective, eds. A. Verma and T. Kochan, Basingstoke: Palgrave MacMillian.

Walsh, J., and Zhu, Y. (2007), "Local Complexities and Global Uncertainties: A Study of Foreign Ownership and Human Resource Management in China," International Journal of Human Resource Management, 18, 249-267.

Wang, H., Appelbaum, R. P., Degiuli, F., and Lichtenstein, N. (2009), "China's New Labour Contract Law: Is China Moving Towards Increased Power for Workers?," Third World Quarterly, 30, 485-501.

Wang, X., Bruning, N., and Peng, S. Q. (2007), "Western High Performance Hr Practices in China: A Comparison among Public-Owned, Private and Foreign-Invested Enterprises," International Journal of Human Resource Management, 18.

Warner, M. (1993), "Human Resource Management 'with Chinese Characteristics'," The International Journal of Human Resource Management, 4, 45-67.

Warner, M. (1996), "Human Resources in the People's Republic of China: The 'Three Systems' Reforms," Human Resource Management Journal, 6, 32-44.

Warner, M. (1997), "Introduction: HRM in Greater China," The International Journal of Human Resource Management, 8, 565-570.

Warner, M. (2002a), "Conclusion: The Future of Chinese Management," Asia Pacific Business Review, 9, 205-223. 
Warner, M. (2002b), "Introduction: Chinese Management in Perspective," Asia Pacific Business Review, 9, 1-20.

Warner, M. (2003), "China's HRM Revisited: A Step-Wise Path to Convergence," Asia Pacific Business Review, 9, 15-31.

Warner, M. (2009a), "'Making Sense' of HRM in China: Setting the Scene," International Journal of Human Resource Management, 20, 2169-2193.

Warner, M. (2009b), "Reassessing Human Resource Management 'with Chinese Characteristics': An Overview," in Human Resource Management 'with Chinese Characteristics', ed. M. Warner, Oxon: Routledge, pp. 1-31.

Whiteley, A., Cheung, S., and Quan, Z. (2000), Human Resource Strategy in China, Singapore: World Scientific.

Whitley, R. (ed.) (1992), European Business Systems: Firms and Markets in Their National Contexts, London: Sage.

Yeung, A., Warner, M., and Rowley, C. (2008), "Guest Editors' Introduction Growth and Globalization: Evolution of Human Resource Management Practices in Asia," Human Resource Management, 47, 1-13.

Zhao, D. (2004), "Lessons from the Practice of Annual Salary System," Shanghai International Investment, 5, 23-24.

Zheng, D. (2007), Human Resource Management (in Chinese), Beijing: Enterprise Management Publishing House.

Zhu, C. J. (2005), Human Resource Management in China: Past, Current and Future Hr Practices in the Industrial Sector, London: Routledge.

Zhu, C. J., Cooper, B., Cieri, H. D., Thomson, S. B., and Zhao, S. (2009), "Devolvement of Hr Practices in Transitional Economies: Evidence from China," in Human Resource Management 'with Chinese Characteristics', ed. M. Warner, Oxon: Routledge, pp. 70-85.

Zhu, C. J., and Dowling, P. J. (2002), "Staffing Practices in Transition: Some Emperical Evidence from China," International Journal of Human Resource Management, 13, 569597.

Zimmerman, A., Liu, X., and Buck, T. (2009), "Employee Tenure and the Nationality of Joint Ventures in China," International Journal of Human Resource Management, 20, 2271-2291. 
Zou, M., and Lansbury, R. D. (2009), "Multinational Corporation and Employment Relations in the People's Republic of China: The Case of Beijing Hyundai Motor Company," International Journal of Human Resource Management, 20, 2349-2369. 